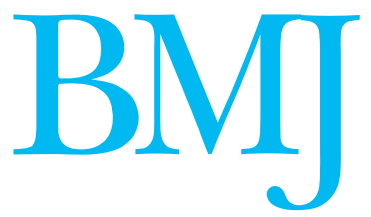

\title{
Breast cancer in men
}

\author{
Treatment is based on results extrapolated from trials for women with breast cancer
}

B reast cancer in men is a rare disease that accounts for less than $1 \%$ of all cancers in men and less than $1 \%$ of all diagnosed breast cancers. ${ }^{1}$ It is a diagnosis for which optimal management is not clearly established and treatment guidelines are scarce. The medical literature regarding breast cancer in men consists mainly of case-control and retrospective studies, and there are no randomised prospective data for this disease. Recent emphasis therefore has been placed on extrapolating data derived from studies of breast cancer in women and using those data as a benchmark for treating men-what's good for the goose is good for the gander.

This year in the United States more than 1600 men will be diagnosed with breast cancer. By comparison, over 200000 women will receive the same diagnosis. ${ }^{1}$ An estimated 500 men will die from breast cancer compared with over 40000 women. ${ }^{1}$ These facts show the lower incidence of breast cancer in men and its comparable higher cancer specific death rate. However, unlike breast cancer in women, where rates have stabilised and seem to be decreasing, the incidence in men younger than 40 seem to be substantially increasing. ${ }^{2}$ This increasing incidence is also reflected in other nations. ${ }^{3}$

Breast cancer in men and women contrasts in the age at diagnosis, the frequency of the histological types, and the frequency of expression of steroid hormone receptor and molecular markers. The median age at diagnosis in men in most series is 68 years compared with 63 years in women. ${ }^{5}$ Men with breast cancer have a higher occurrence of ductal histology. More than $85 \%$ of all cases are invasive ductal carcinomas; in women the frequency of ductal histology is $70-75 \%$. Oestrogen, androgen, and progesterone steroid receptor expression is also higher in men with breast cancer. $^{67}$ Her-2/neu, a proto-oncogene cell surface receptor, has been found to be expressed in $0-95 \%$ of men with breast cancer-the expression rate varies according to the number of patients examined. In women $20-40 \%$ of patients have Her-2/neu positive tumours and an association with adverse prognosis is established. The significance of Her-2/neu in breast cancer in men remains unclear. While germ line genetic mutations of BRCA 1 in women can confer a $60-80 \%$ lifetime risk for breast cancer, mutations in BRCA 1 do not increase the risk of breast cancer in men. ${ }^{8}$ BRCA 2 mutations, however, do appear to be a
Despite the biological differences, clinical outcomes for breast cancer in men are similar to those for women when they are matched for age, treatment, and stage of cancer. ${ }^{469}$ Older series have reported worse outcomes but were confounded by comparably later stage at presentation, long duration of symptoms before treatment, failure to account for nodal disease, and suboptimal treatment. Most men are treated with mastectomy. However, without established criteria for adjuvant treatment, men are more likely than women to receive suboptimal radiation treatment. ${ }^{4}$ Several randomised trials have established limited surgery plus radiation as the standard of care for women. In some series of men with breast cancer, however, they receive limited surgery without radiation. Likewise, post mastectomy radiation criteria are also established for women. Yet some men receive radiation inappropriately, which perhaps results in significant cardiac doses, contributing to decreased survival.

A recent analysis at our centre of men with breast cancer who were not treated with radiation after mastectomy showed that current guidelines for radiation treatment for women are applicable to men with breast cancer and can help optimise local regional control. ${ }^{10}$ Data derived from other studies at our centre show that men treated with adjuvant doxorubicin based chemotherapy for stage II or III disease had five year survival rates greater than $85 \%{ }^{11}$ Furthermore using the guidelines established for women can help optimise systemic control. Currently we recommend chemotherapy for men with breast cancer with positive nodes, tumours larger than $1 \mathrm{~cm}$, and hormone receptor negative metastases. ${ }^{12}$ We also recommend hormonal treatment for five years. Yet many men with breast cancer do not receive chemotherapy or hormonal treatment, although they have a higher rate of hormone receptor positive tumours, and tamoxifen has been shown to improve survival in men. ${ }^{4}$

Men with breast cancer, in summary, are older, more likely to have hormone receptor positive disease, nodal metastases, and advanced stage disease than women with breast cancer. ${ }^{9}$ They are also likely to receive suboptimal treatment. ${ }^{4}$ The published data to date indicate a need for benchmarks that can be examined prospectively to determine the optimal treatment of breast cancer in men. We currently use and recommend for men the same guidelines used for treatment of breast cancer in women. As the incidence of breast cancer is currently rising in younger men we should generate new data that will contribute towards 
guidelines for determining when treatment for men and women should be the same or differ, and that will help optimise treatment.

George H Perkins assistant professor of radiation oncology

Breast Radiation Oncology Service, Nelly B Connelly Breast Cancer Center Research Program, University of Texas MD Anderson Cancer Center, 1515 Holcombe Blvd, Houston TX, 77030 USA (gperkins@mdanderson.org)

Lavinia P Middleton assistant professor of surgical pathology

Breast Pathology Service (lpmiddleton@mdanderson.org)

Supported in part by grant T32 CA 77050-02 awarded by the US Department of Health and Human Services and the US National Cancer Institute.

Competing interests: None declared.

1 Jemal A, Thomas A, Murray T, Thun M. Cancer statistics 2002. CA Cancer J Clin 2002;52:23-47.

2 National Cancer Institute, DCCPS, Surveillance Research Program, Cancer Statistics Branch, Surveillance, Epidemiology, and End Results Program Public-Use Data Tapes 1973-1998. August Submission, Released April 2001.
3 Sasco AJ, Lowenfels AB, Pasker-deJong P. Review article: epidemiology of male breast cancer. A metanalysis of published case-control studies and discussion of selected aetiological factors. Int J Cancer 1993;53:538-49. discussion of selected aetiological factors. Int J Cancer 1993;53:538-49.
Bland KI, Menck HR, Scott-Conner CE, Morrow M, Winchester DJ, WinBland KI, Menck HR, Scott-Conner CE, Morrow M, Winchester DJ, Win-
chester DP. The national cancer data base 10 -year survey of breast carcinoma treatment at hospitals in the United States. Cancer 1998;83:126273.

5 Rayson D, Erlichman C, Suman VJ, Roche PC, Wold LE, Ingle JN, et al. Molecular markers in male breast carcinoma. Cancer 1998;83:1947-55.

6 Scott-Conner CH, Jochimsen PR, Menck HR, Winchester DJ. An analysis of male and female breast cancer treatment and survival among of male and female breast cancer treatment and survival amon
demographically identical pairs of patients. Surgery 1999;125:775-81.

demographically identical pairs of patients. Surgery 1999;125:775-81.
Shoker BS, Jarvis C, Sibson DR, Walker C, Sloane JP. Oestrogen receptor expression in the normal and pre-cancerous breast. $J$ Pathol 1999;188:237-44.

8 Friedman LS, Gayther SA, Kurosaki T, Gordon D, Noble B, Casey G, et al. Mutation analysis of BRCA 1 and BRCA 2 in a male breast cancer population. Am J Hum Genet 1997;60:313-9.

9 Giordano S, Cohen D, Buzdar AU, Perkins GH, Hortobagyi GN. A population-based analysis of male breast cancer. J Clin Oncol 2003;21:in press.

10 Perkins GH, Middleton LP, Garcia SM, Strom EA, McNeese MD, Singletary SE, et al. Male breast carcinoma: outcomes and predictors of local-regional failure for patients treated without radiation therapy. Breast Cancer Res Treat 2002;76:121.

11 Patel HZ, Buzdar AU, Hortobagyi GN. Role of adjuvant chemotherapy in male breast cancer. Cancer 1989;64:1583-5.

12 Giordano SH, Buzdar AU, Hortobagyi GN. Review. Breast cancer in men. Ann Intern Med 2002:137:678-87.

\title{
Clinical trials for tomorrow funded by the MRC
}

\author{
Future policy report raises several unanswered questions
}

$\mathrm{T}$ The Medical Research Council has an honourable tradition of supporting high quality randomised controlled trials. It funded one of the most celebrated early trials-of streptomycin for pulmonary tuberculosis, published in the BMJ in 1948. ${ }^{1}$ It has just published a commendably short 12 page report to determine its future policy and approach to randomised controlled trials ${ }^{2}-$ so what does it say?

It is encouraging that the MRC intends to promote trials of so called complex interventions, where several components act both independently and interdependently.This is precisely where substantial methodological challenges are to be tackled-just what is the intervention, what outcomes are relevant, and how can the results be generalised to clinical practice? For example, the results of a trial of care in a stroke unit compared with care in a general medical ward must depend on the nature of the stroke unit and general medical ward being compared-their staffing, treatment policies, duration of admission, and so on. But although ring fenced funding for the development stage of such trials is welcome, the allocation of $£ 250000$ (\$405 000; €352 000) annually will hardly be enough to put trial proposals "on a more even footing with those involving drugs." After all, the pharmaceutical companies spend millions to get their products to the stage of large trials of efficacy.

The MRC has "begun discussions" with the Department of Health about the overwhelming difficulties researchers have in accessing funding from the NHS for the treatment to be tested and for the time of the practitioners involved. And not before time. The department is supposed to underpin these costs and must be told just how monumental this problem is, particularly when the intervention is not a drug. Equipment may be required, such as compression stockings for a trial of prevention of deep venous thrombosis or coils for a trial of coiling versus clipping to prevent rupture of intracranial aneurysms. Investigations may be needed, such as an extra computed tomography scan of the head in a trial of thrombolysis in acute stroke. Or an extra outpatient appointment for follow up for the trial, which also might well provide better care than is generally available in the NHS, where waiting time targets for new outpatients are emphasised rather than proper outpatient management of long term conditions. A trial might need people, for example, to provide physiotherapy or cognitive behaviour therapy. It is disheartening for the Department of Health to insist on evidence based treatments if it is not prepared to contribute properly to getting the evidence in the first place. Surely research in the NHS is not an optional extra.

The MRC wants trial collaborators to have more incentives, so more recognition for collaboration in a trial, both on the NHS side in the annual appraisals and on the university side in the research assessment exercise. Although the cynical view is "some hope," this is a worthwhile aim, so good luck to Sir Iain Chalmers, who will lead on this initiative. Another part of the same problem is that potential collaborators can so easily be swayed by the competition, in other words by the very considerable financial incentives for participating in industry trials. The MRC document is completely silent on this crucial issue-why join an MRC trial if an industry trial will provide a research nurse to help with routine NHS work and some new gear that the hospital trust won't buy? The MRC-and Department of Health-will need to provide very substantial incentives for trusts and practitioners if they are to compete with the might of the pharmaceutical industry.

The MRC acknowledges the increasing bureaucratic and regulatory sludge, which is such a disincentive to trialists and a major burden to trial 